\title{
Inhibition of the leucine-rich repeat protein lingo-1 enhances RGC survival in optic nerve injury
}

\author{
YADAN QUAN, YALI WU, ZONGYI ZHAN, YANGFAN YANG, XIAOTAO CHEN, KAILI WU and MINBIN YU
}

\author{
State Key Laboratory of Ophthalmology, Zhongshan Ophthalmic Center, \\ Sun Yat-Sen University, Guangzhou, Guangdong 510060, P.R. China
}

Received July 3, 2018; Accepted March 26, 2019

DOI: $10.3892 /$ etm.2019.8250

\begin{abstract}
Leucine-rich repeat and immunoglobulin-like domain-containing nogo receptor-interacting protein 1 (lingo-1) is selectively expressed on neurons and oligodendrocytes in the central nervous system and acts as a negative regulator in neural repair, implying a potential role in optic neuropathy. The aim of the present study was to determine whether adeno-associated virus serotype 2 (AAV2) vector-mediated transfer of lingo-1 short hairpin RNA could reduce nerve crush-induced axonal degeneration and enhance axonal regeneration following optic nerve (ON) injury in vivo. The expression of lingo-1 was knocked down in vivo using a green fluorescent protein (GFP)-tagged AAV2 encoding lingo-1 shRNA via intravitreal injection in adult Sprague-Dawley rats. Silencing effects of AAV2-lingo-1-shRNA were confirmed by detecting GFP labelling of RGCs, and by quantifying lingo-1 expression levels with reverse transcription-quantitative polymerase chain reaction and western blotting. Rats received an intravitreal injection of AAV2-lingo-1-shRNA or negative control shRNA. The ON crush (ONC) injury was performed 2 weeks after the intravitreal injection. RGC density, lesion volume of the injured $\mathrm{ON}$ and the visual electrophysiology [flash visual evoked potential (F-VEP)] at different time points post-injury were determined. Transduction with lingo-1-shRNA decreased lingo-1 expression levels and promoted RGC survival following ONC. Lingo-1-shRNA promoted $\mathrm{ON}$ tissue repair and functional recovery. The mechanism underlying the effect of AAV2-lingo-1-shRNA on RGCs may be the phosphorylation of protein kinase B (Akt) at Ser473 and activation of the Akt signaling pathway acting downstream of lingo-1. The results of the current study indicate
\end{abstract}

Correspondence to: Professor Minbin Yu, State Key Laboratory of Ophthalmology, Zhongshan Ophthalmic Center, Sun Yat-Sen University, 54 South Xianlie Road, Guangzhou, Guangdong 510060, P.R. China

E-mail: yuminbin@mail.sysu.edu.cn

Key words: leucine-rich repeat and immunoglobulin-like domain-containing nogo receptor-interacting protein 1 , optic nerve crush, protein kinase B, retinal ganglion cell, visual function that the inhibition of lingo-1 may enhance RGC survival and facilitate functional recovery following ON injury, representing a promising potential strategy for the repair of optic neuropathy.

\section{Introduction}

Glaucoma, a group of diseases of the optic nerve (ON) causing axon damage and permanent visual function impairment, is the leading cause of irreversible blindness worldwide (1-3). The glaucomatous optic neuropathy involves both anterograde (retina to visual cortex) (4) and retrograde (visual cortex to retina) degeneration spreading under various pathological conditions (4). The eye-to-brain pathway is composed of retinal ganglion cell (RGC) connections to corresponding subcortical targets $(5,6)$. Damage of the adult mammalian central nervous system (CNS) leads to irreversible neuron loss thereby preventing recovery of numerous neural functions $(7,8)$.

An important target of neuroprotection is to identify the restricting elements that regulate CNS repair (6). Leucine-rich repeat and immunoglobulin-like domain-containing nogo receptor-interacting protein 1 (lingo-1), a transmembrane protein, is expressed on neurons and oligodendrocytes in the CNS and functions as a component of the negative growth regulatory protein NGR1 (NgR1)/p75 and NgR1/tumor necrosis factor receptor superfamily member 19 signaling complexes (9-12). Lingo-1 negatively regulates axonal sprouting and myelination in the CNS by binding to Nogo-A, myelin associated glycoprotein (13), and oligodendrocyte myelin glycoprotein to inhibit the function of growth factors. Lingo-1 expression is upregulated in degenerative diseases and CNS injuries including spinal cord injury, multiple sclerosis, Parkinson's disease and glaucoma $(3,12)$. Lingo-1 was reported to bind to epidermal growth factor receptor (EGFR) or brain-derived neurotrophic factor (BDNF)/NT-3 growth factors receptor to inhibit survival pathways in neurons (10-12,14-16) and oligodendrocyte differentiation by binding to erythroblastic leukemia viral oncogene homolog 2 (12). Inhibition of lingo-1 function using RNA interference, dominant negative lingo-1, soluble lingo-1 lacking the cytoplasmic domain $(10,11,15,16)$ and anti-lingo-1 antibodies $(15,17,18)$ revealed promising effects on promoting neuronal survival, axon regeneration and oligodendrocyte differentiation in animal models of degenerative diseases and CNS injuries $(9,12,16,19,20)$. 
Experimental ON lesion is a model frequently used to study the molecular mechanisms underlying CNS neuronal death and axonal growth in vivo (21-24). The ON crush (ONC) mimics certain responses of neurons in the CNS to injury, including glaucomatous optic neuropathy and optic neurotrauma (5). In animal models of ONC, injured RGC axons fail to regenerate following mechanical crush, eventually leading to RGC death (25). A study using ON transection models revealed that lingo-1 was upregulated following ON transfection, and inhibition of the function of lingo-1 with lingo-1 antagonist rescued RGCs from cell death (14). In the present study, the authors delineated the protein kinase B (Akt) pathways as the predominant effectors in the $\mathrm{ON}$ transection procedure. A previous study also suggested that some leucine-rich repeat (LRR) Ig-containing proteins can influence growth factors by modulating EGFR signaling-associated pathways (15). Lingo-1 gene expression is increased when adult neurons are exposed to traumatic injuries $(12,14-16,26)$. These results indicate that lingo-1 may be involved in neuron injury responses. As observed in the current study, lingo-1 may impede axon maintenance and the structural integrity of RGCs. However, whether inhibition of lingo-1 may enhance RGC survival during $\mathrm{ONC}$ and the underlying mechanism in vivo, remain unknown.

The current study hypothesized that lingo-1 short hairpin RNA (shRNA) may exhibit neuroprotective effects for the ON and RGCs, resulting in enhanced RGC survival and preserved visual function. The current study used an adeno-associated virus serotype 2 (AAV2) vector encoding lingo-1 shRNA for the targeted inhibition of lingo-1 in RGCs. AAV2-lingo-1-shRNA constructs were injected into the vitreous bodies in rats. Following the viral transfer, the ONC injury was performed to investigate the effects of this treatment on neurodegeneration in vivo. The current study subsequently investigated the potential mechanisms underlying these effects. The results indicate that the targeted inhibition of lingo-1 may promote RGC survival and axon integrity, and prompt the recovery of neurological functions via Akt phosphorylation at Ser473.

\section{Materials and methods}

Animals. A total of 240 Sprague-Dawley rats of both sexes (age, 8-10 weeks; sex ratio: 1:1; weight, 200 $\pm 20 \mathrm{~g}$; Experimental Animal Center of Sun Yat-sen University, Guangzhou, China) were handled in accordance with the Association for Research in Vision and Ophthalmology statement on the use of animals in research. All experimental protocols and the ethical care of the rats were reviewed and approved by the Institutional Animal Care and Use Committee of the Zhongshan Ophthalmic Center, Sun Yat-sen University (approval no. 2016187). The rats had free access to food and water in an environmentally controlled room at a temperature of $23^{\circ} \mathrm{C}$ and $55 \%$ humidity with a 12 -h light/dark cycle. The rats were randomly divided into 3 groups: Sham operation group, negative control shRNA (NC-shRNA) group and lingo-1-shRNA group as described previously $(6,7,26)$.

AAV2 production. The lingo-1 shRNA AAV2 vectors were constructed to specifically silence the lingo-1 gene (Shanghai GeneChem Co., Ltd., Shanghai, China). The following sequences were used: Lingo-1-shRNA, 5'-TAAGCACAA CATCGAAATTGAATTCAAGAGATTCAATTTCGATGT TGTGCTTTTTTTTC-3' and NC-shRNA, 5'-CCGGTTCTC CGAACGTGTCACGTTTCAAGAGAACGTGACACGTTC GGAGAA-3'. A hybrid of the cytomegalovirus and chicken $\beta$-actin promoters was used to control the expression of lingo-1. The reporter green fluorescent protein (GFP) gene was linked to the shRNA via an internal ribosome entry site. The lingo-1 shRNA and NC sequences were packaged into the AAV2 supplied by Shanghai GeneChem Co., Ltd. The final titer of AAV2-lingo-1 shRNA was $\sim 10^{12} \mathrm{TU} / \mathrm{ml}$.

Intravitreal injections. The intravitreal injections were conducted as described previously (7,27). Following anesthesia with inhalant isoflurane, a puncturing hole was made near the ora serrata of the right eye. Vectors $(3 \mu l)$ were injected into the vitreal chamber with a 33 gauge Hamilton ${ }^{\mathrm{TM}}$ needle (Hamilton Company, Reno, NV, USA) under a dissecting microscope. The left eye was left untreated. Care was taken to avoid inflammation, damage to the lens or induction of cataracts (28). Any rats with cataract or inflammation induced by injection were euthanized and were not included in the dataset. Subsequent experimentation (sham operation group, $n=40$; negative control shRNA (NC-shRNA) group, $n=44$; lingo-1-shRNA group, $n=50$ ) was performed 2 weeks following the injections to allow viral expression. All injections were performed by a researcher blind to the treatment conditions.

ONC surgery. Prior to surgery, animals were anesthetized by intraperitoneal injection of $50 \mathrm{mg} \mathrm{kg}^{-1}$ sodium pentobarbital (Sinopharm Chemical Reagent Co., Ltd., Shanghai, China), and the right eye was numbed with a drop of $0.5 \%$ proparacaine hydrochloride (Alcon Laboratories, Inc., Fort Worth, TX, USA). ONC surgery was performed as previously described with minor modifications (29). Briefly, an incision was made through the conjunctiva at the upper conjunctival fornix to expose the sclera. Following exposure of the ON, self-closing Jeweler's fine forceps (cat. no. 11254-20; Dumont \#5; Fine Science Tools, Inc., Foster City, CA, USA) were used to crush the $\mathrm{ON}$ at a distance $\sim 2 \mathrm{~mm}$ behind the posterior pole of the eye for $10 \mathrm{sec}$ (Fig. 1) (6). Following surgery, eyes subjected to the ONC were closely monitored for several days for any signs of bleeding. Any rats with eyes with vascular damage or abnormalities of the optic fundus following surgery were excluded from the following examination and data analysis. A total of 18 rats were excluded due to vascular damage or abnormalities of the optic fundus following surgery.

Flash visual evoked potential (F-VEP) recording. Rats were examined for functional recovery based on the measurement of F-VEP. An electrophysiological diagnostic apparatus (RETI-port/scan 21; Roland Consult Stasche \& Finger GmbH, Brandenburg an der Havel, Germany) was used, in accordance with the International Society for the Clinical Electrophysiology of Vision standard for electrophysiological studies (7). The F-VEP was recorded under deep anesthesia with inhalant isoflurane (verified by the absence of a tail-pinch reaction). Following 20 min of dark adaptation, F-VEP was recorded with silver needle electrodes, which were implanted supraperiosteally over the bilateral visual cortex (V1). A reference 
A)

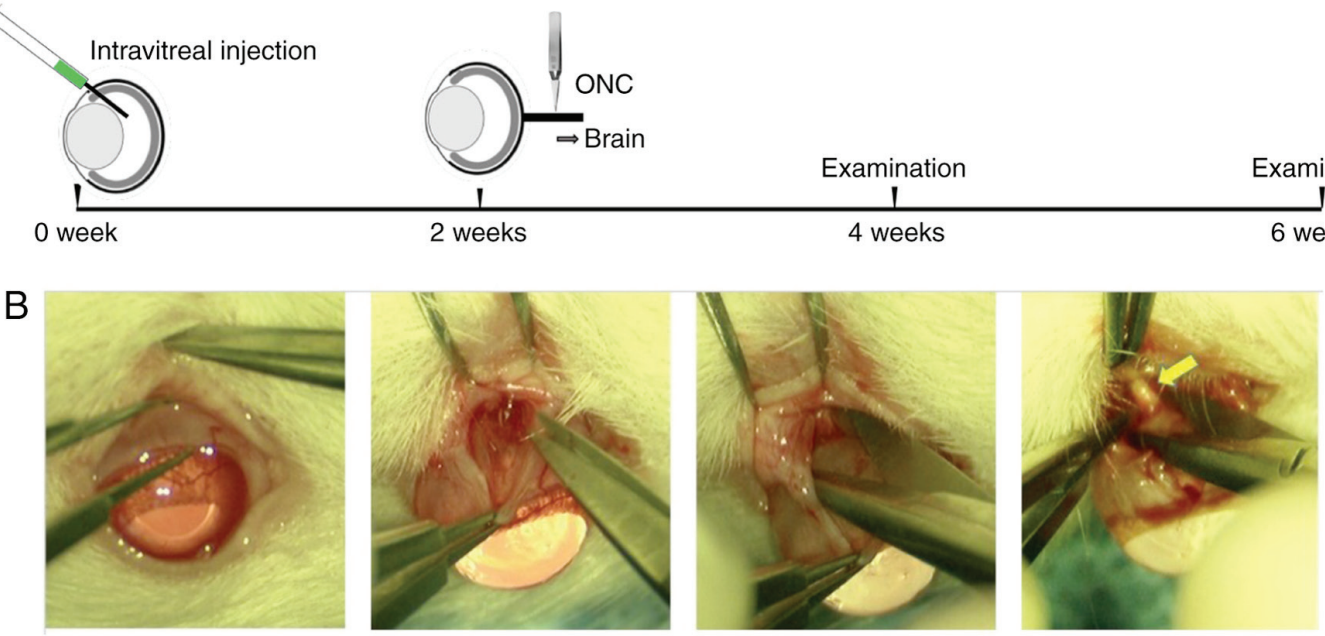

Figure 1. Experimental design. (A) Schematic timeline of the experimental procedure. Two weeks after intravitreal injection of adeno-associated virus vectors, $\mathrm{ONC}$ was performed on the injected eyes. Analysis, including morphological, functional and electrophysiological changes of RGCs/ONs, was performed prior to ONC, and 2 and 4 weeks after ONC. (B) ONC procedure (magnification, x6). The yellow arrow indicates the site of the ONC. ONC, optic nerve crush; RGC, retinal ganglion cell.

electrode was implanted subcutaneously at the midpoint of the binoculus and ground electrode was implanted into the tail of each rat. The test room was illuminated with a dim red safelight. White flash stimuli were delivered at a frequency of $2 \mathrm{~Hz}, 250 \mathrm{~ms}$ for analysis. The responses were amplified 10,000 times and band-pass-filtered from 1 to $1,000 \mathrm{~Hz}$, and superposition was conducted 100 times $(18,30)$. Recordings of evoked potentials were taken from bilateral cortices for each experiment; simulation was unilateral, and the other eye was covered with an opaque eyeshade.

The parameters recorded were the latency of N1 waves and N1 amplitude (measured from N1 wave peak to P1 wave trough). All of the parameter values were measured automatically by the reto-port/scan 21 computer output, and the average of the three successive measurements was calculated.

Immunostaining. Rats were sacrificed 4 weeks after ONC surgery. After anesthesia and transcardial perfusion with normal saline followed by $4 \%$ paraformaldehyde (PFA), the eyes and ONs were harvested and post-fixed in 4\% PFA overnight. The ONs were then transferred to PBS then placed in 30\% sucrose and frozen at $-80^{\circ} \mathrm{C}$ in Optimal Cutting Temperature compound (Thermo Fisher Scientific, Inc., Waltham, MA, USA). The $\mathrm{ON}$ was sectioned using a sledge microtome, cutting longitudinally or transversely at $10 \mu \mathrm{m}$. Immunofluorescent staining was performed in a blocking solution at room temperature for $1 \mathrm{~h}$ (20\% normal donkey serum, cat. no. ab7475; Abcam, Cambridge, UK; 0.1\% Triton-X-100 in PBS, Solarbio, Shanghai, China). Primary antibodies were applied overnight at $4^{\circ} \mathrm{C}$ and, after PBS washes, sections were incubated with the appropriate primary antibodies overnight, and the secondary antibody for $1 \mathrm{~h}$ at room temperature. Primary antibodies were as follows: Rabbit-anti-RNA-binding protein with multiple splicing (RBPMS, 1: 200; cat. no. ABN1376; EMD Millipore, Billerica, MA, USA), to label RGCs; rabbit-anti-GFP (1: 300; cat. no. ab2556; Abcam), to detect GFP; rabbit-anti-p-Ser473 (1:200; cat. no. D9E; Cell Signaling Technology, Inc., Danvers, MA, USA), to label phosphorylated Akt Ser473; and rabbit
anti-Lingo-1 (1:200; cat. no. ab23631, Abcam), to detect lingo-1 expression. The Alexa Fluor 488 goat anti-rabbit or anti-guinea pig (cat. nos. A-11008, A-11073, Invitrogen; Thermo Fisher Scientific, Inc.), or Alexa Fluor 594 goat anti-rabbit (cat. no. A-11012, Invitrogen; Thermo Fisher Scientific, Inc.) were used as secondary antibodies. Immunofluorescent labeling was analyzed with a fluorescence microscope (Axio Observer Z1; Zeiss AG, Oberkochen, Germany).

Hematoxylin-eosin (HE) staining. The rat eyes and the ONs were collected as aforementioned and used for HE staining (Fig. 1A). The tissue specimens were dehydrated in gradient alcohol after 4\% PFA fixation for $2 \mathrm{~h}$ at room temperature and immersed for $5 \mathrm{~min}$ in xylene before embedding in wax. The specimens were incubated at $60^{\circ} \mathrm{C}$ overnight then embedded in liquid paraffin, immersed in water and cut into $10-\mu \mathrm{m}$ thick slices. After deparaffinization and gradient rehydration, the slices were stained with hematoxylin for $10 \mathrm{~min}$ at room temperature and washed with running water for $5 \mathrm{~min}$. Depigmentation was performed in $1 \%$ hydrochloric acid alcohol. Sections were washed with running water for $5 \mathrm{~min}$, then washed with 50,70 and $80 \%$ alcohol for $3 \mathrm{~min}$ at each concentration and stained with $0.5 \%$ eosin for $5 \mathrm{~min}$ at room temperature. Subsequently, samples were washed with 95 and $100 \%$ alcohol for 3 min each and treated with xylene for $10 \mathrm{~min}, \mathrm{o}$-xylene for $2 \mathrm{~min}$ and $\mathrm{m}$-xylene for $2 \mathrm{~min}$. The slices were sealed by neutral resin and observed under a light microscope (Zeiss AG).

Cell number quantification. After euthanasia and perfusion of the rat (as described above), the superior portion of the eye was marked with a marking pen and then the whole eye was enucleated and fixed in $4 \%$ PFA at $4^{\circ} \mathrm{C}$. After $1 \mathrm{~h}$, the eye was rinsed in PBS and the anterior segment removed to create an eye cup. The retina was removed from the eye cup and placed with the ganglion cell layer facing up into a culture dish; four cuts were made to allow the retina to lay flat. Flattened retinae were fixed in $4 \%$ PFA at $4^{\circ} \mathrm{C}$ overnight, subsequently blocked 
and incubated at $4{ }^{\circ} \mathrm{C}$ for $1 \mathrm{~h}$ in a solution $(0.3 \%$ Triton-X-100, $10 \%$ donkey serum and $0.01 \%$ sodium azide in PBS; Sorlarbio Science \& Technology Co.,Ltd.) containing a primary antibody (EMD Millipore) against RBPMS, an RGC marker used for RGC quantification (31). RGC intensity was compared in the flat mount retinas of AAV2-lingo-1 shRNA-injected animals and control animals injected with saline. Each RBPMS ${ }^{+}$cell was subsequently counted in the four quadrants of the retina using an epifluorescence microscope and included in the quantification of the RGC numbers in different experimental conditions. The number of RGC bodies was quantified at $1 \mathrm{~mm}$ from the optic disc in four quadrants. The density of surviving RGCs was calculated per $\mathrm{mm}^{2}$ ( $\mathrm{n}=5$ rats per group) manually.

Western blotting. ON protein lysates were extracted from tissues ( $\mathrm{n}=5$ per group) by incubating in RIPA buffer (EMD Millipore) supplemented with PMSF (EMD Millipore). Protein samples were separated by SDS-PAGE (NuPAGE 4-12\% Bis-Tris gel) and transferred to PVDF membranes (EMD Millipore). The membranes were blocked with 5\% nonfat dry milk containing $0.1 \%$ Tween-20 in PBS for $1 \mathrm{~h}$ at room temperature and incubated with primary antibodies at $4^{\circ} \mathrm{C}$ overnight. The following primary antibodies were used at 1:1,000 dilution: Lingo-1, p-Akt (p-Ser473; cat. no. D9E, Cell Signaling Technology, Inc.), Akt (Cell Signaling Technology, Inc.), GAPDH (cat. no. PA-987; Thermo Fisher Scientific, Inc.). Super Signal West Pico Chemiluminescent Substrate kit (cat. no. 34580; Thermo Fisher Scientific, Inc.) was applied to visualize protein bands, band intensity was analyzed with ImageJ v6.0 software (National Institutes of Health, Bethesda, MD, USA). Protein levels in tissues were quantified by densitometry and normalized to GAPDH, respectively (phospho-Akt levels were normalized to total Akt levels).

Reverse transcription-quantitative PCR (RT-qPCR). To investigate molecular events associated with lingo-1 inhibition, changes in gene expression were evaluated by qPCR . The following primers were used for qPCR: Lingo-1, 5'-CTTTCCCCTTCGACATCAAGAC-3' and 3'-CAGCAG CACCAGGCAGAA-5'; GAPDH, 5'-ACAGTCAGCCGC ATCTTCTT-3' and 3'-GACAAGCTTCCCGTTCTCAG-5'. GAPDH was used for normalization. qPCR was performed using unfixed ONs 28 days after ONC in the lingo-1-shRNA and NC-shRNA groups. ONs were dissected in ice-cold PBS and immediately immersed into RNAlater reagent (Qiagen $\mathrm{GmbH}$, Hilden, Germany). RNA was extracted using a RNeasy kit (Qiagen $\mathrm{GmbH}$ ) and reverse-transcribed using iScript cDNA Synthesis kit (Bio-Rad Laboratories, Inc., Hercules, CA, USA) to obtain cDNA. qPCR was performed using the $\mathrm{iQ}^{\mathrm{TM}} \mathrm{SYBR}^{\circledR}$ Green Supermix kit according to manufacturer's protocol (Bio-Rad Laboratories, Inc.). The following thermocycling conditions were used: Initial denaturation at $95^{\circ} \mathrm{C}$ for $10 \mathrm{~min} ; 40$ cycles of $95^{\circ} \mathrm{C}$ for $30 \mathrm{sec}$ and $60^{\circ} \mathrm{C}$ for $1 \mathrm{~min}$; and a final extension at $72^{\circ} \mathrm{C}$ for $1.5 \mathrm{~min}$. The $2^{-\Delta \Delta \mathrm{Cq}}$ method was used to quantify the relative changes in gene expression (32). The average $\mathrm{C}_{\mathrm{q}}$ was calculated for the target gene and GAPDH and the $\Delta \mathrm{C}_{\mathrm{q}}\left(\mathrm{C}_{\mathrm{q}, \text { target }} \mathrm{C}_{\mathrm{q}, \mathrm{GAPDH}}\right)$ values were analyzed. All qPCR experiments were performed with three technical replicates.
Statistical analysis. Statistical analyses were performed using GraphPad Prism 6.0 (GraphPad Software, Inc., La Jolla, CA, USA). Normality tests and variance heterogeneity tests were performed on all datasets. Statistical analysis was performed using Student's t-test for comparisons between two groups or by one-way analysis of variance followed by Tukey's post-hoc tests for comparisons of more than two groups. Error bars are presented as mean \pm standard error (S.E.). $\mathrm{P}<0.05$ was considered to indicate a statistically significant difference.

\section{Results}

Lingo-1 shRNA knocks down lingo-1 expression in RGCs. It has been reported that lingo-1 is detected in the retina and ON of adult rats $(12,16)$. To analyze the role of lingo-1 in RGCs, RGCs were transduced with a GFP-expressing lingo-1 shRNA vectors via intravitreal injections. Two weeks after the injection, GFP expression was observed in flat mount retinas (Fig. 2A and B), and the results suggested that the transfection was successful. Furthermore, western blot analysis 2 weeks after AAV2 injection revealed that the expression of lingo-1 was knocked down by AAV2-lingo-1-shRNA compared with AAV2 NC-shRNA ( $\mathrm{P}<0.01$; Fig. 2C-E). Taken together, these results indicate that shRNA-mediated knockdown in vivo lead to significant alterations in lingo-1 expression in RGCs in rats.

Inhibiting lingo-1 expression increases the RGC cell density. To investigate whether changes in lingo-1 expression levels affect RGCs survival in rats with ON-injury, the densities of RGCs were quantified in whole-mount retinas of sham ONC, NC-shRNA and AAV2-lingo-1-shRNA injected rats. RGC densities were quantified by RBPMS-positive cell counts on flat-mounted retinas. The RGC cell density of each group is presented in Fig. 3. Four weeks after ONC, the RGC density was significantly higher in the lingo-1-shRNA-injected group compared with the control group $\left(908.3\right.$ cells $/ \mathrm{mm}^{2}$ vs. 338.3 cells $/ \mathrm{mm}^{2}$, respectively). There was a significant increase in RGC density in the lingo-1-shRNA-treated groups compared with NC-shRNA in all four quadrants of retina $(\mathrm{P}<0.01$; Fig. 3). Together, these results revealed that transfection of lingo-1-shRNA enhanced the survival rate of RGCs after $\mathrm{ONC}(\mathrm{P}<0.01 ;$ Fig. 3). Together, these data suggested that lingo-1-shRNA can reduce RGC loss during ON injury.

Lingo-1-shRNA reduces the lesion volume of the injured $O N$. Tissue repair was estimated by calculating the size of the lesion cavities in injured ONs. The size of the lesion cavity was calculated in HE-stained sections (longitudinal and transverse ON sections) at 4 weeks post-injury to detect tissue repair (Fig. 4). The tissue did not narrow from the outer edge of the lesioned ON. The outer margins near the lesion site relatively retained structural integrity, however, multiple cavities were observed in HE staining of ONs (Fig. 4A and $\mathrm{H}$ ). In rats treated with lingo-1-shRNA, the total cavity area in the longitudinal plane was $21.9 \%$ smaller compared with the NC-shRNA group (27930.0 pixels vs. 34034.7 pixels, respectively; P<0.05; Fig. 4C, F and J). The differences of total cavity area between the lingo-1-shRNA group and the NC-shRNA group at the retrograde and antegrade sites were insignificant (Fig. 4B, D, E, G, I and K). Differences in lesion volume were 
A

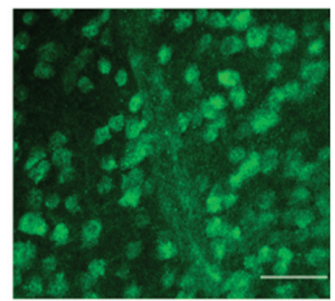

B

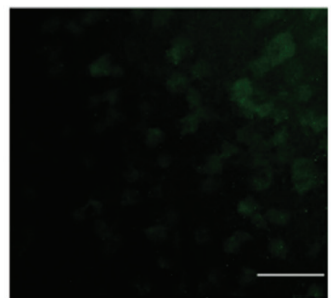

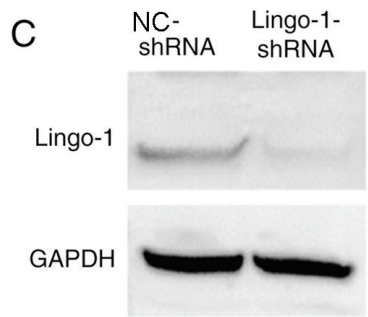
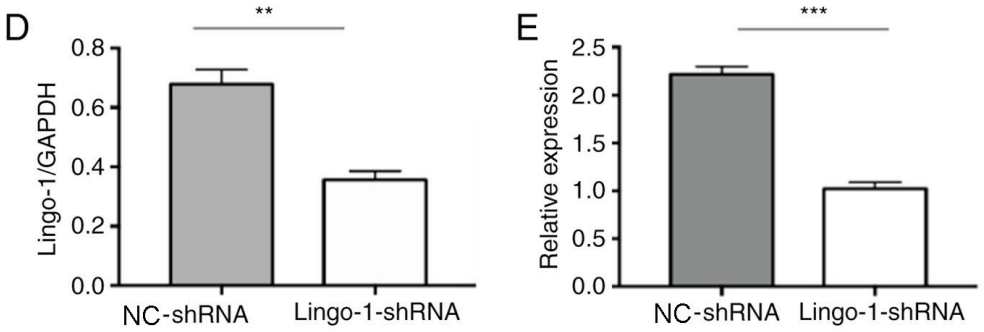

Figure 2. Lingo-1-shRNA delivery exhibits high transfection efficiency in RGCs. Representative images of (A) lingo-1-shRNA and (B) NC-shRNA GFP immunostaining in flat mount retina samples 2 weeks post injection. Scale bar, $50 \mu \mathrm{m}$. (C) Representative western blot images and (D) semi-quantitative data of lingo-1 protein expression 2 weeks after injection. (E) Alterations in the mRNA levels of lingo-1 in the optic nerves. Error bars represent standard error of the mean, $\mathrm{n}=5$. ${ }^{* * *} \mathrm{P}<0.01$ and ${ }^{* * *} \mathrm{P}<0.001$. Lingo-1, leucine-rich repeat and immunoglobulin-like domain-containing nogo receptor-interacting protein 1 ; RGC, retinal ganglion cell; NC-shRNA, negative control shRNA; shRNA, short hairpin RNA; GFP, green fluorescent protein.
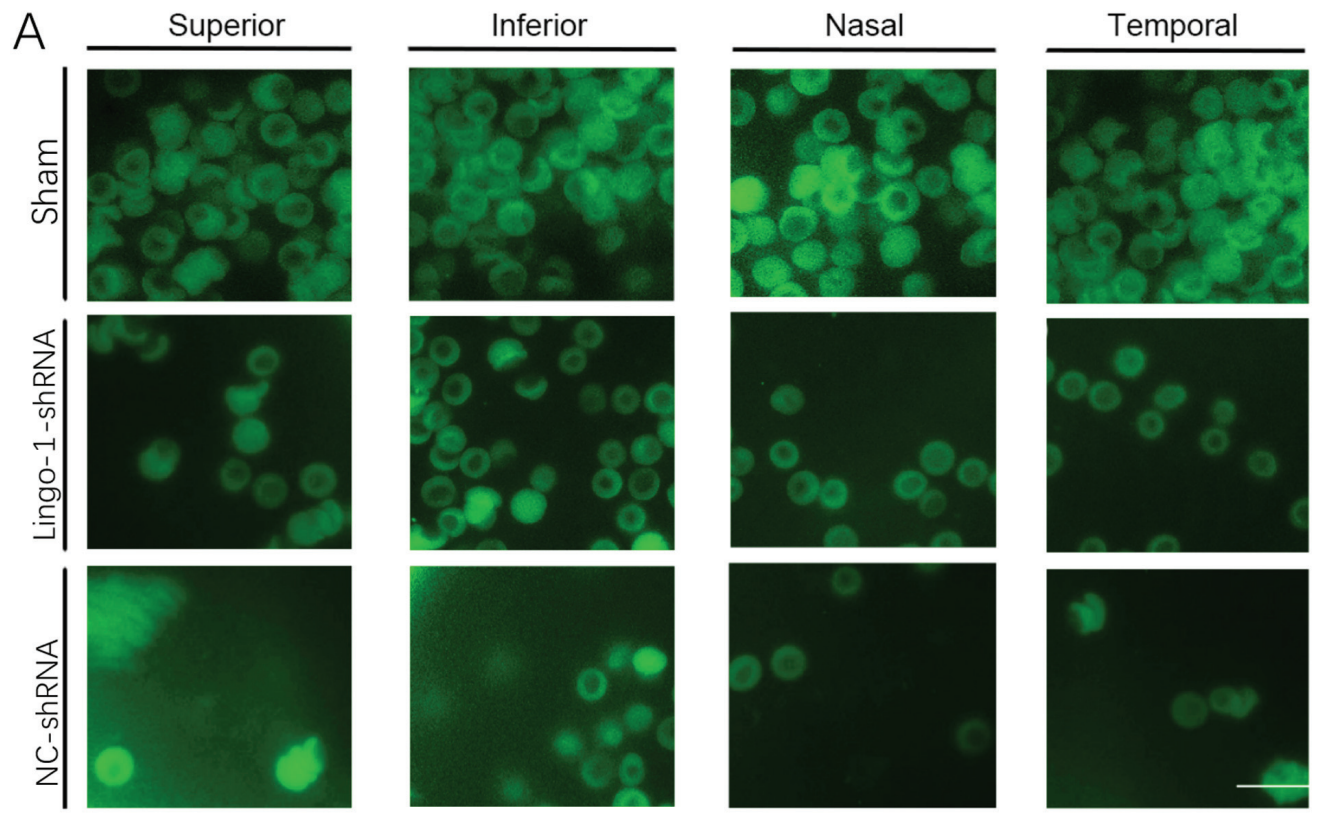

\section{B}
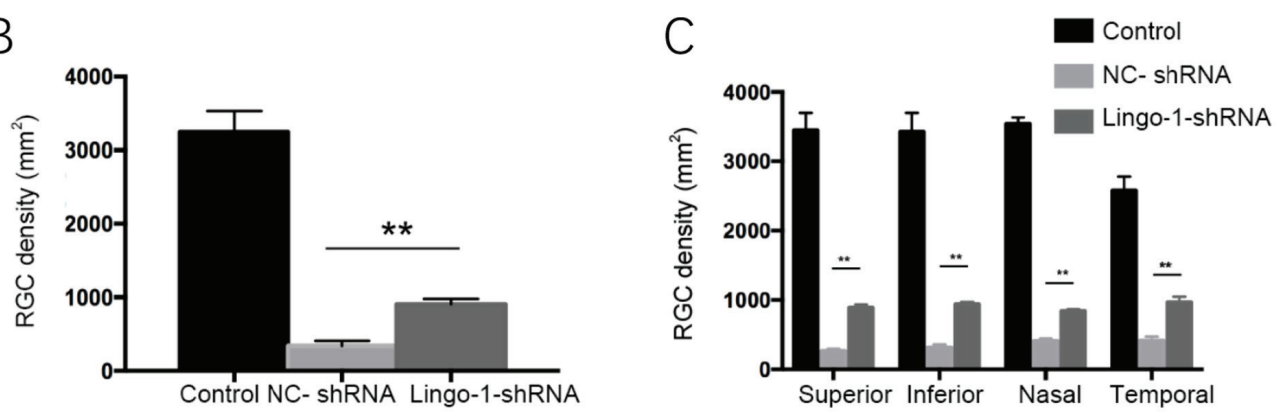

Figure 3. RGC survival in different groups following optic nerve crush injury. Two weeks after optic nerve crush, surviving RGCs were observed in the in the superior, inferior, nasal and temporal quadrants of retinal flat mounts via immunofluorescent staining for RNA-binding protein with multiple splicing. Representative images were captured at $1 \mathrm{~mm}$ from the optic disc. (A) Representative images of RGCs treated with sham control, NC-shRNA or AAV2-lingo-1-shRNA following optic nerve injury. Scale bar=50 $\mu \mathrm{m}$; magnification, x100. (B) Quantitative analysis of the average number of surviving RGCs in whole retina samples. (C) Density of surviving RGCs in different retinal quadrants. ${ }^{* *} \mathrm{P}<0.01$. Lingo-1, leucine-rich repeat and immunoglobulin-like domain-containing nogo receptor-interacting protein 1; RGC, retinal ganglion cell; NC-shRNA, negative control shRNA; shRNA, short hairpin RNA. 

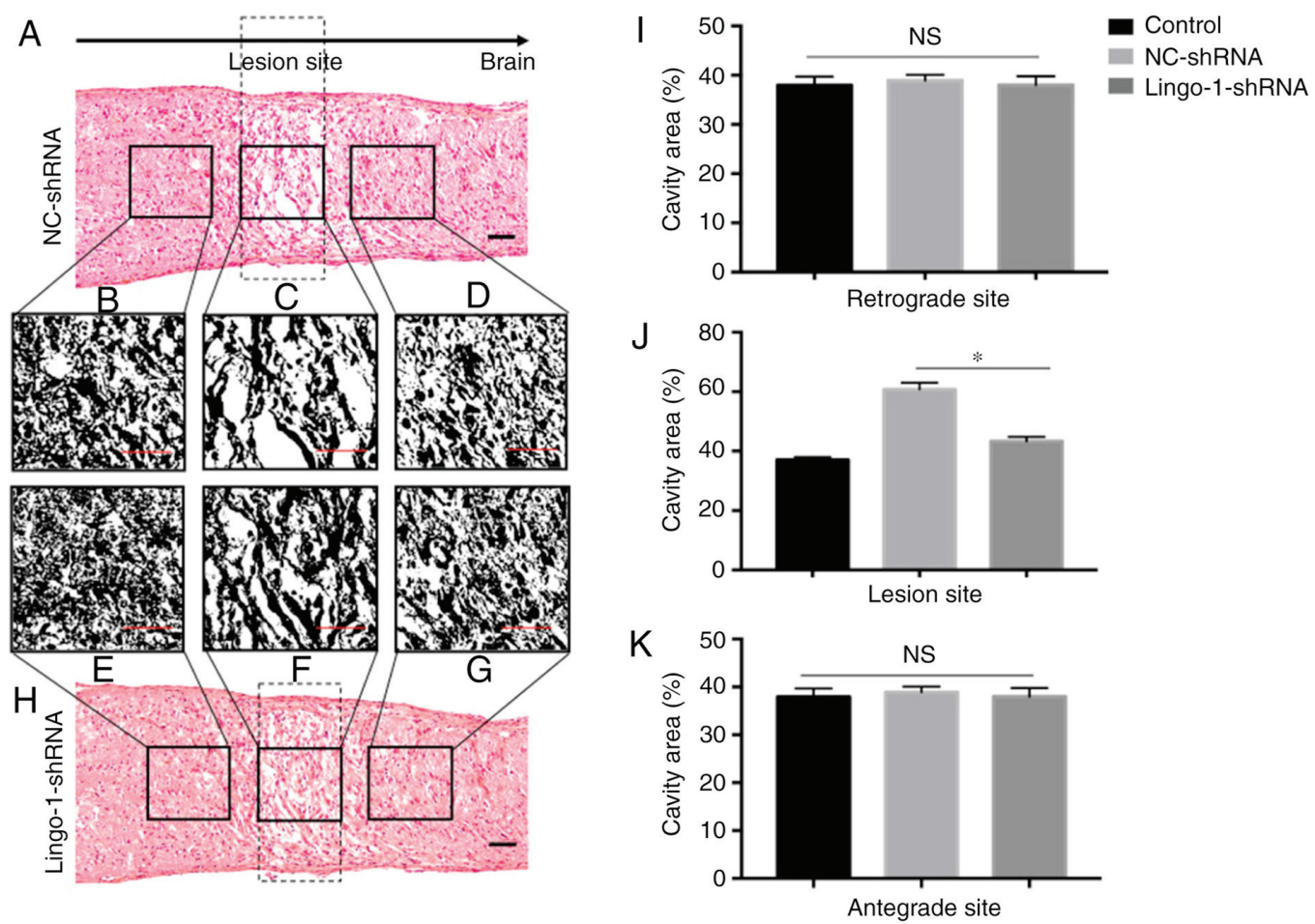

Figure 4. Longitudinal histological sections of optic nerves. (A) Representative histological section of the optic nerve in the NC-shRNA group. (B-D) Details of histological alterations in the optic nerve following ONC in the NC-shRNA group. (E-G) Details of histological alterations in the optic nerve following ONC in the lingo-1-shRNA group. (H) Representative histological section of the lingo-1-shRNA group. scale bar=50 $\mu \mathrm{m}$. Analysis nerve cavity areas in NC-shRNA, lingo-1-shRNA and sham surgery groups at the (I) retrograde site, $(\mathrm{J})$ lesion site and (K) antegrade site ( $\mathrm{n}=6$ mice per group). ${ }^{*} \mathrm{P}<0.05$. Lingo-1, leucine-rich repeat and immunoglobulin-like domain-containing nogo receptor-interacting protein 1; ONC, optic nerve crush; NC-shRNA, negative control shRNA; shRNA, short hairpin RNA; NS, not significant.

also observed in transverse sections (Fig. 5), the cavities in lingo-1-shRNA-treated rats were significantly smaller and less numerous than those in the NC-shRNA group.

Targeted inhibition of lingo-1 preserves F-VEP after ONC. F-VEPs were measured to test the functional recovery after ONC. The N1 waves were detected before, and 2 and 4 weeks post-injury (Fig. 6A). The ONC procedure lead to a delay in peak latencies of N1 waves. Both in lingo-1-shRNA and NC-shRNA group, longer N1 wave latencies were observed at 2 weeks $(\mathrm{P}<0.05)$ and 4 weeks post-injury compared with the respective control groups $(\mathrm{P}<0.01$; Fig. $6 \mathrm{C}$ and $\mathrm{D})$. The P1-N2 amplitudes 4 weeks post-injury in the sham, NC-shRNA and lingo-1-shRNA groups were $36.27 \pm 7.81,5.27 \pm 3.56$, $17.06 \pm 2.89 \mu \mathrm{V}$, respectively (Fig. 6C; Table I). Compared with the NC-shRNA group, the lingo-1-shRNA-treated group exhibited a decreased latency of $\mathrm{N} 1$ waves at 2 weeks $(\mathrm{P}<0.01)$ and 4 weeks post-injury $(\mathrm{P}<0.001$; Fig. $6 \mathrm{D})$. No complete restoration of $\mathrm{N} 1$ waves was observed in the current study. The results suggest that lingo-1-shRNA treatment can partially preserve the visual function in the ONC model. Detailed data of F-VEP recording are listed in Table I.

Knockdown of lingo-1 promotes Akt activation in the ON after injury. To analyze the mechanisms underlying the neuroprotective effects observed, the current study aimed to determine whether the Akt signaling pathway was involved. Phosphorylation of Akt is an important survival signal for neurons and for RGCs after ON injuries $(5,33,34)$. Considering the neuroprotective role of Akt signaling $(12,14,21)$, it was hypothesized that inhibition of lingo-1 may promote Akt activation. The effects of lingo-1-shRNA on Akt phosphorylation were determined by measuring total Akt and pAkt (at Ser473) before and after ONC.

pAkt expression in intact $\mathrm{ON}$ was very low and not detectable by immunostaining (Fig. 7A). The difference of pAkt/Akt level between the 3 groups was statistically insignificant before the injury and 2 weeks post-operation (data not shown). However, 4 weeks after ONC, western blotting revealed that there was a low level of Akt phosphorylation in ON tissues in the sham and NC-shRNA groups (Fig. 7B). p-Akt levels were very low in sham ONs but increased 1.65 -fold 4 weeks after ONC, indicating that the neuroprotective activity may be mediated through partial Akt phosphorylation at Ser473 in response to lingo-1 silencing.

\section{Discussion}

The current study examined the strategy of delivering lingo-1 shRNA vectors for ON injury repair. Knockdown of lingo-1 significantly promoted functional recovery and increased RGCs survival, providing neuroprotection through the activation of Akt signaling in the lesioned ONs. The current study indicated that intravitreal delivery of lingo-1 shRNA vectors may be an efficient and effective approach for the treatment of optic neuropathy.

Delivering lingo-1 shRNA vectors into rats subjected to ONC allowed for the evaluation of whether lingo-1 shRNA 

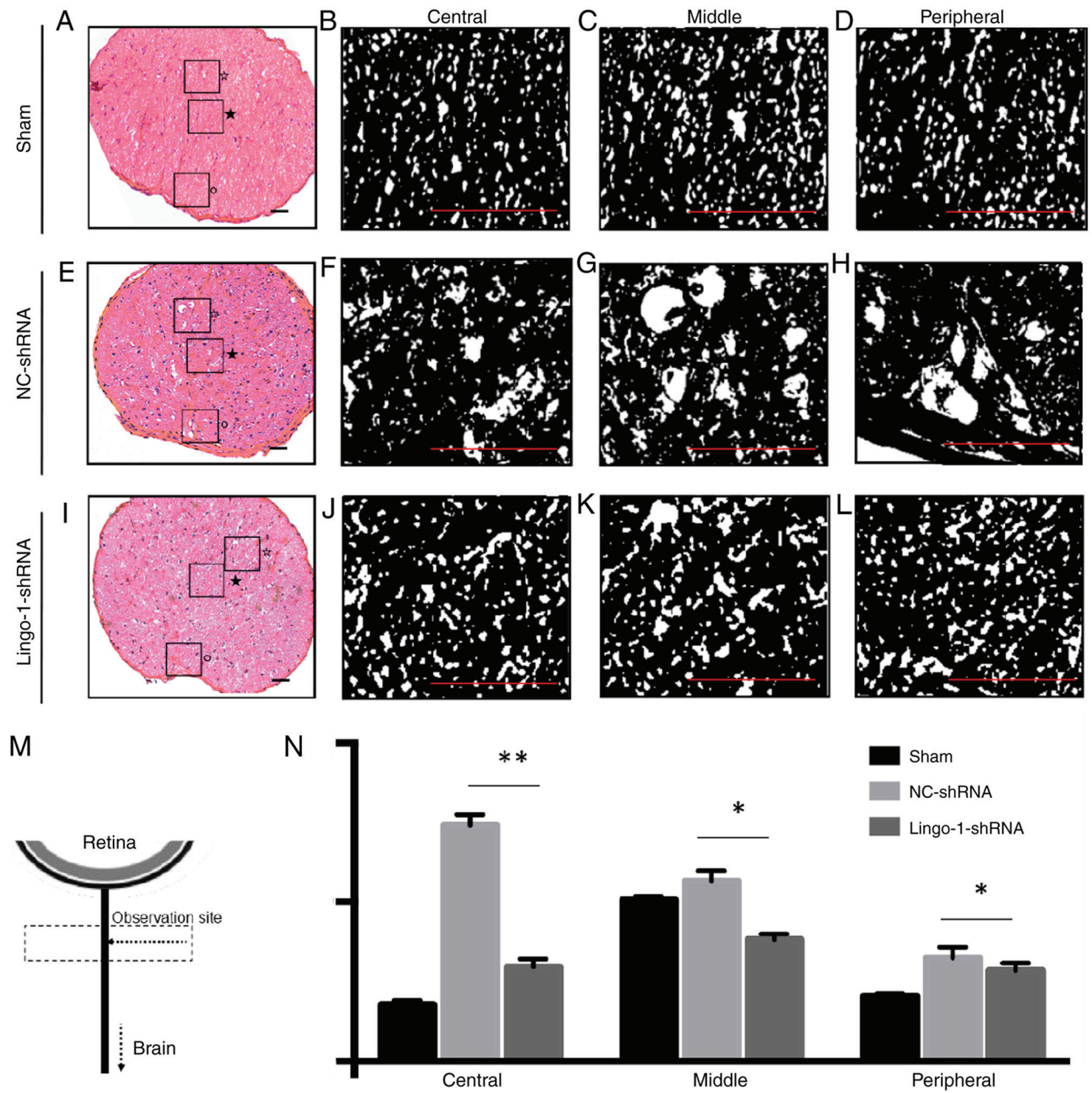

Figure 5. Transverse histological sections of optic nerves. (A) Representative histological section of the sham ONC group. Details of histological alterations of the (B) central, (C) middle and (D) peripheral part of the optic nerve of the sham ONC group. (E) Representative histological section of the NC-shRNA group. Details of histological alterations of the $(\mathrm{F})$ central, $(\mathrm{G})$ middle and $(\mathrm{H})$ peripheral part of the optic nerve of the NC-shRNA group. (I) Representative histological section of the lingo-1-shRNA group. Details of histological alterations of the (J) central, $(\mathrm{K})$ middle and $(\mathrm{L})$ peripheral part of the optic nerve of the lingo-1-shRNA group. *, central area; ${ }^{*}$, middle area; ${ }^{\circ}$, peripheral area. Scale bar $=100 \mu \mathrm{m}$. (M) Schematic drawing showing the observation site of transverse histological sections of optic nerves. (N) Quantitative analysis of nerve cavity areas in the three groups revealed that the injury damaged the central, middle and the peripheral parts of optic nerves, and the damage was most severe in the central parts of the optic nerves. $\mathrm{n}=5$. ${ }^{*} \mathrm{P}<0.05$ and ${ }^{* *} \mathrm{P}<0.01$. Lingo- 1 , leucine-rich repeat and immunoglobulin-like domain-containing nogo receptor-interacting protein 1; ONC, optic nerve crush; NC-shRNA, negative control shRNA; shRNA, short hairpin RNA.

may promote RGC survival after ONC in vivo. The ON is a part of the CNS, injury of which is difficult to regenerate. The ON is composed of RGC axons, injury of which may lead to permanent vision loss. The anterograde ON damage causes the death of a large number of RGCs (5). Furthermore, gradual axonal degeneration following ON injury causes the death of RGCs, which ultimately leads to irreversible loss of visual function $(4,22,27,28,34,35)$. Therefore, promoting the survival of injured RGCs is crucial to the treatment of optic neuropathy. In the current study, RGCs transfected with lingo-1 shRNA vectors were administered intravitreally to knock down lingo-1 expression in the ON. The downregulation of lingo-1 protein expression confirmed successful delivery of AAV in vivo.
RGC function in animal models of ONC was quantified using the overall F-VEP response method, which allows for the detection of changes in the anterograde degeneration in glaucoma and optic neurotrauma. The N1 latency strongly reflects the function of nerve impulse conduction and myelin sheath integrity $(28,34)$. The $\mathrm{N} 1$ amplitude demonstrates the receptive function of RGCs and the number of synaptic contacts between functional axons and their targets in V1 cortex $(4,36)$. Injury or degeneration of the $\mathrm{ON}$ leads to latency delay and amplitude decrease of N1 waves to varying degrees (37). In the current study, following ONC, F-VEP measurements revealed that rats treated with lingo-1 shRNA exhibited a higher amplitude and a shorter latency of $\mathrm{N} 1$ waves compared with the NC-shRNA group, indicating a protection on visual function. There results 
A

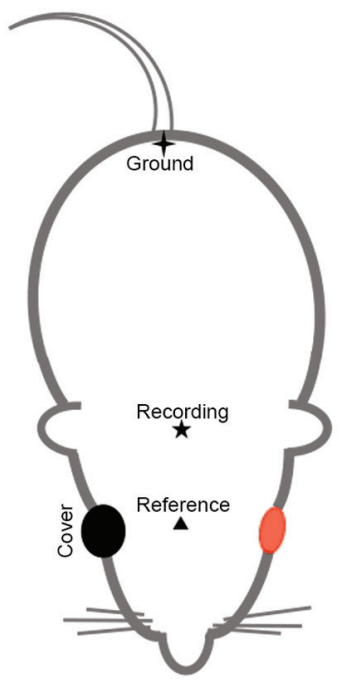

B

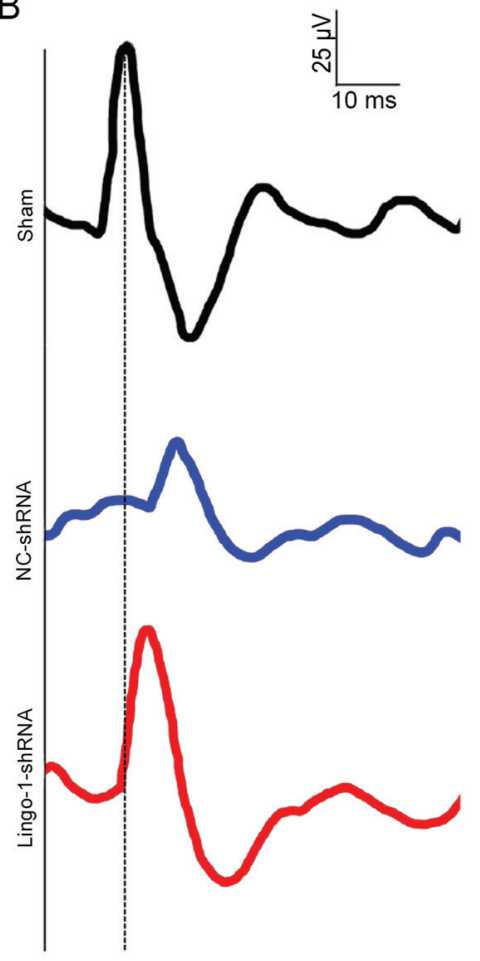

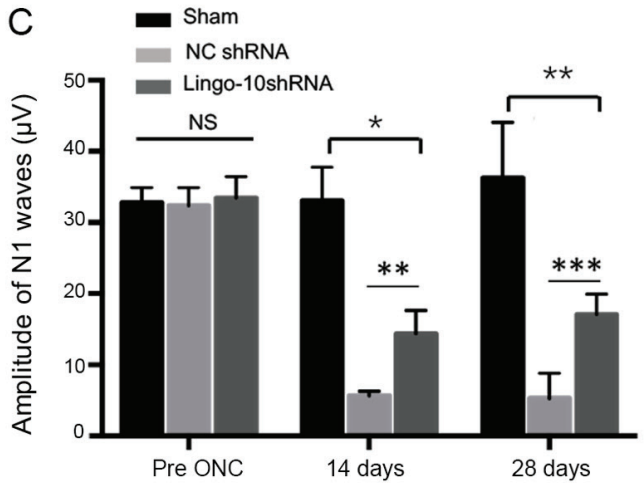

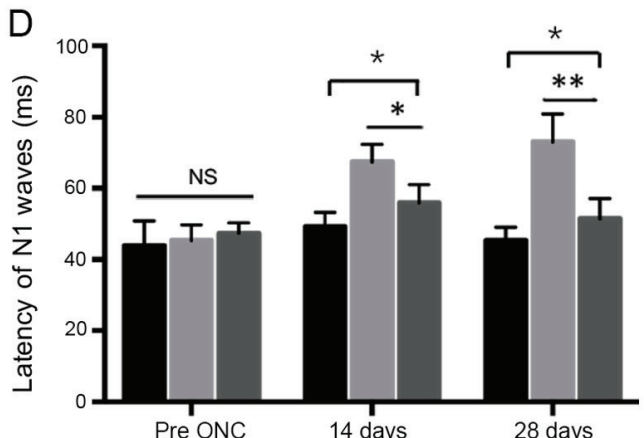

Figure 6. Evaluation of the recovery of injured optic nerves using the F-VEP wave pattern. (A) Locations of silver needle electrodes. ${ }^{\mathbf{\Delta}}$, the reference electrode; ${ }^{\star}$, the recording electrode; ${ }^{+}$, the ground electrode. The red color indicated the testing eye of the rat. (B) Representative F-VEP tracings 4 weeks following ONC in the sham surgery, NC-shRNA and lingo-1-shRNA groups. Y-axis scale, $25 \mu \mathrm{V}$; $\mathrm{x}$-axis scale, $10 \mathrm{~ms}$. (C) N1 amplitude 2 and 4 weeks following ONC (D) N1 latency 2 and 4 weeks following ONC. Error bars represent standard error of the mean, $\mathrm{n}=10 .{ }^{*} \mathrm{P}<0.05,{ }^{* * *} \mathrm{P}<0.01$ and ${ }^{* * *} \mathrm{P}<0.001$. Lingo-1, leucine-rich repeat and immunoglobulin-like domain-containing nogo receptor-interacting protein 1; NC-shRNA, negative control shRNA; shRNA, short hairpin RNA; F-VEP, flash visual evoked potential; NS, not significant.

indicate that lingo-1 negatively regulated RGC survival and damage-resistance ability of axons, and postponed the functional recovery of RGC after optic neuropathy.

In addition, as confirmed by HE staining, treatment with lingo-1-shRNA significantly reduced the ON lesion volume, which reflected the extent of tissue repair and contributed to functional recovery of RGCs after ONC. The proximal ON damage reduces the number of $\mathrm{ON}$ fibers in degenerative and traumatic neuropathy $(5,22,25,27,28)$. In the current study, knockdown of lingo-1 decreased the extent of RGC loss. Apart from the survival rate of RGCs, axon repair also serves an important role in vision recovery following ON injury (12). In the current study, following ONC, the injured area did not shrink around the lesion site. In NC shRNA group, more axons survived were observed near the margin of lesioned area, however, severe damage in the central area of the ONs was observed 4 weeks post injury. In the current study, lingo-1-shRNA application represented a meaningful approach to enhance the capacity of RGC survival morphologically and functionally, as evidenced by RGC quantification, assessment of the cavity volume in $\mathrm{ON}$ and F-VEP measurement.

Lingo-1 is a CNS-specific membrane-associated glycoprotein, which is known to be a potent inhibitor of neural survival and axonal regeneration $(15,20,38)$. In animal models of Parkinson's disease, upregulation of lingo-1 coincided with decreased EGFR levels, suggesting that lingo-1 may inhibit the EGFR/Akt signaling pathway in dopamine neurons $(12,14,15)$. Anti-lingo-1 antibody underwent clinical trial in subjects with relapsing remitting or secondary progressive multiple sclerosis (clinicaltrials.gov; Identifier: NCT01244139) (16). The role of lingo-1 in neurodegeneration has been extensively studied, yet caveats still remain in understanding the mechanism by which it contributes to optic neuropathy.

Similar to other neurodegenerative diseases, in the current study, lingo-1-shRNA protected against RGC death and axon loss after ONC $(15,39)$. These results indicated that lingo-1 inhibition may be efficient in promoting functional recovery of axons after ON injury. Due to the tetramer structure burying a large area into the cell membrane, it has been hypothesized that lingo- 1 could function at the sites of neuronal pathways to terminate axon growth $(15,39)$. In neurons, lingo-1 normally inhibits the elongation and axonal growth $(9,12)$. Therefore, knocking down lingo-1 expression may maintain structural and functional integrity of RGCs. It has been reported that blocking lingo-1 function with lingo-1 antagonists may protect cells from apoptosis via inhibition of RhoA activation, and enhance neuronal survival through activation of the PI3K/Akt pathways in chronic glaucoma and acute ON transaction models $(5,14,40)$. Furthermore, the neuroprotective activity through activation of the Akt intracellular signals is independent of RhoA $(33,41)$. The phosphorylation of Akt at Ser473 and Thr-308 could be independently regulated in different biological activities $(33,38,42)$. Thus, phosphorylation of Ser473 did not require concomitant phosphorylation of Thr-308 by PI3K during neural injury (43). In the current 
Table I. Amplitude and latency of flash-visual evoked potential.

A, Latency of N1-P1 waves, $\mu \mathrm{V}(\mathrm{n}=10)$

\begin{tabular}{|c|c|c|c|c|}
\hline Timepoint & Sham ONC & NC-shRNA & Lingo-shRNA & P-value \\
\hline Pre ONC & $43.97 \pm 6.93$ & $45.37 \pm 4.35$ & $47.33 \pm 2.99$ & 0.662 \\
\hline 2 weeks & $45.23 \pm 4.07$ & $65.86 \pm 6.37$ & $55.98 \pm 5.04$ & 0.002 \\
\hline 4 weeks & $49.23 \pm 3.69$ & $59.03 \pm 3.94$ & $50.88 \pm 6.45$ & 0.0004 \\
\hline
\end{tabular}

B, Amplitude of N1 waves, ms $(n=10)$

\begin{tabular}{|c|c|c|c|c|}
\hline Timepoint & Sham ONC & NC-shRNA & Lingo-shRNA & P-value \\
\hline Pre ONC & $32.7 \pm 2.14$ & $32.37 \pm 2.53$ & $33.43 \pm 2.99$ & 0.554 \\
\hline 2 weeks & $33.03 \pm 4.73$ & $5.65 \pm 0.68$ & $14.35 \pm 3.29$ & 0.011 \\
\hline 4 weeks & $36.27 \pm 7.81$ & $5.27 \pm 3.56$ & $17.06 \pm 2.89$ & 0.002 \\
\hline
\end{tabular}

Data are presented as the mean \pm standard error. Lingo-1, leucine-rich repeat and immunoglobulin-like domain-containing nogo receptor-interacting protein 1; ONC, optic nerve crush; NC-shRNA, negative control shRNA; shRNA, short hairpin RNA.
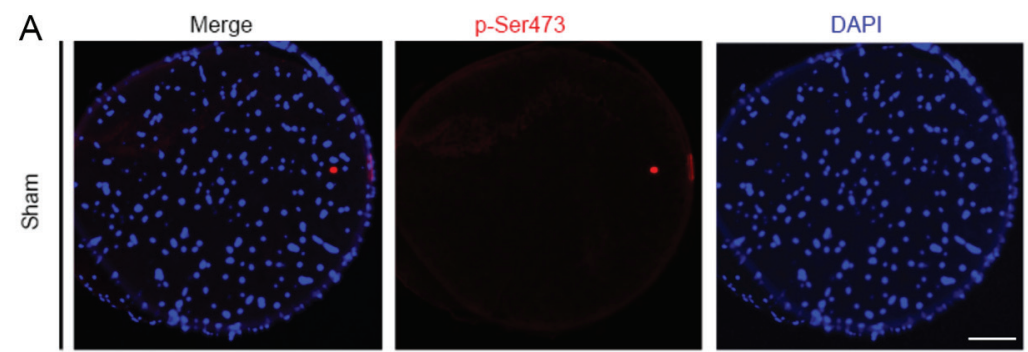

B
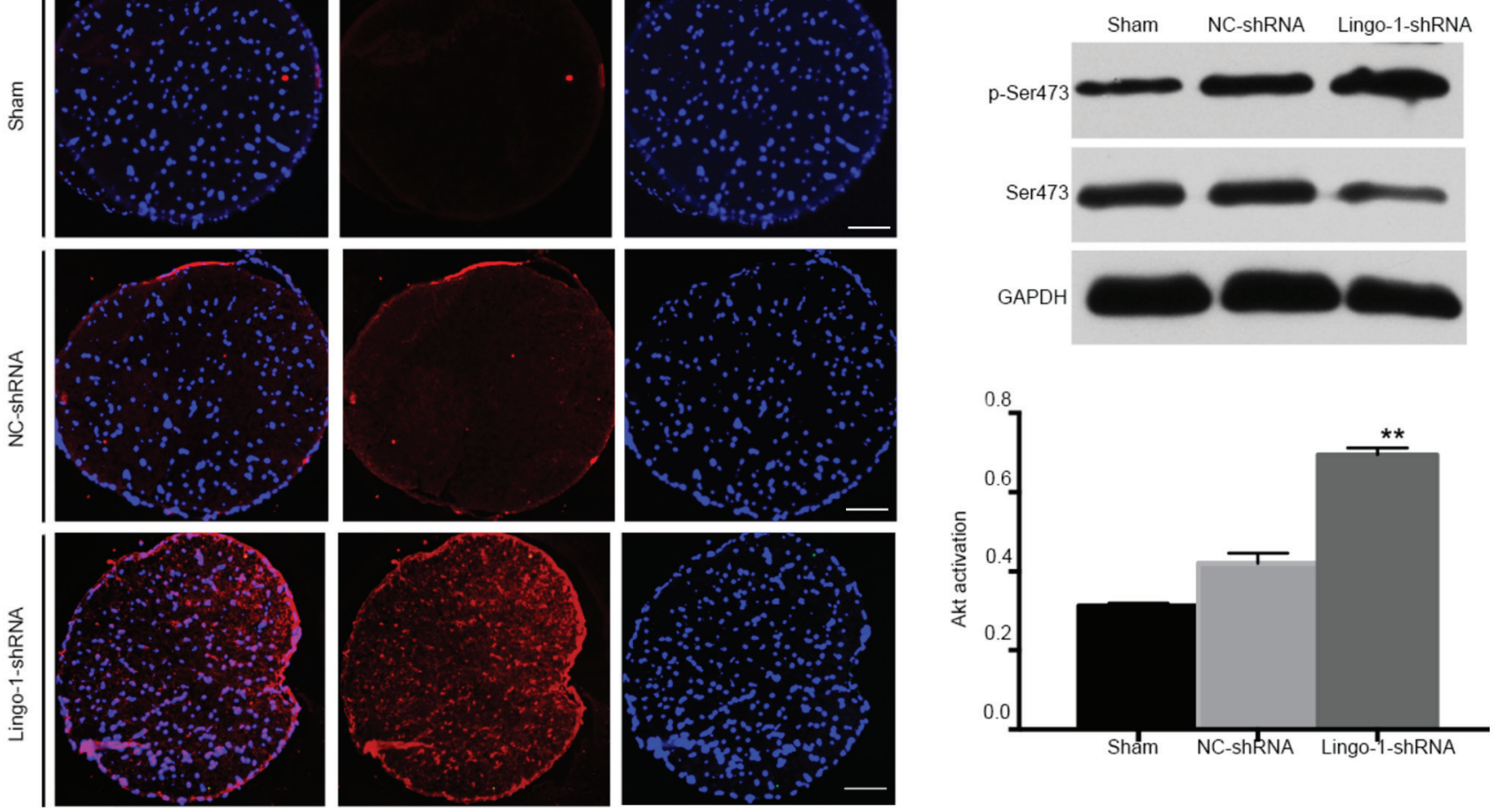

Figure 7. p-Ser473 expression in optic nerves. (A) Representative immunofluorescent staining images presenting p-Ser473 expression (red; scale bar=100 $\mu \mathrm{m}$ ) in sham surgery, NC-shRNA and lingo-1-shRNA groups. (B) Western blot analysis of Akt activation of the injured optic nerves. The ratio of p-Akt to total Akt expression levels was calculated four weeks following optic nerve injury. Total protein level was normalized to $\beta$-actin levels, $\mathrm{n}=5$. ${ }^{* *} \mathrm{P}<0.01 \mathrm{vs}$. the NC-shRNA group. Lingo-1, leucine-rich repeat and immunoglobulin-like domain-containing nogo receptor-interacting protein 1; p-, phosphorylated; NC-shRNA, negative control shRNA; shRNA, short hairpin RNA; Akt, protein kinase B.

study, the phosphorylation of Akt at Ser473 was elevated after lingo-1-shRNA treatment, and this result is consistent with a previous study (15). Upregulation of p-Ser473 was also observed in vivo in an animal model of Parkinson's disease in lingo-1 knockout mice (15). Therefore, inhibition of lingo-1 appears to function through mechanisms similar to those of other neuroprotective factors, such as BDNF (43) and erythropoietin (13) which rescue RGCs after axotomy by activating Akt via Ser473 phosphorylation. In the current study, the activation of Akt through Ser473 phosphorylation in response to lingo-1 silencing not only enhanced RGC survival but also preserved axon integrity. The present study 
had certain limitations and whether the transportation of p-AKT from lesioned axons to RGC soma remains to be determined.

In conclusion, the present study provided evidence that lingo-1 is a negative regulator of the survival and integrity maintenance of RGCs. The delivery of lingo-1-shRNA appears to be a promising potential strategy for enhancing RGC survival for individuals with traumatic or glaucomatous neurodegeneration. The influence of lingo-1 on Akt signaling was confirmed, however, the exact mechanism underlying these changes requires further investigation.

\section{Acknowledgements}

Not applicable.

\section{Funding}

The present study was supported by the Guangdong Innovative Research Team Program (grant no. 2015A030312016) and National Natural Science Foundation of China (grant no. 81870655).

\section{Availability of data and materials}

The datasets used and/or analyzed during the current study are available from the corresponding author on reasonable request.

\section{Authors' contributions}

All authors approved the final version of the manuscript. $\mathrm{YQ}, \mathrm{KW}$ and $\mathrm{MY}$ conceived and designed the experiments. YQ, YW, ZZ, XC, YY and KW performed the experiments. YQ and $\mathrm{YW}$ analyzed the data. YQ and MY wrote the manuscript.

\section{Ethics approval and consent to participate}

All experimental protocols and the ethical care of the rats were reviewed and approved by the Institutional Animal Care and Use Committee of the Zhongshan Ophthalmic Center, Sun Yat-sen University (approval no. 2016187).

\section{Patient consent for publication}

Not applicable.

\section{Competing interests}

The authors declare that they have no competing interests.

\section{References}

1. Bourne RR, Stevens GA, White RA, Smith JL, Flaxman SR, Price H, Jonas JB, Keeffe J, Leasher J, Naidoo K, et al: Causes of vision loss worldwide, 1990-2010: A systematic analysis. Lancet Glob Health 1: e339-e349, 2013.

2. Jonas JB, Aung T, Bourne RR, Bron AM, Ritch R and Panda-Jonas S: Glaucoma. Lancet 390: 2183-2193, 2017.

3. Stevens GA, White RA, Flaxman SR, Price H, Jonas JB, Keeffe J, Leasher J, Naidoo K, Pesudovs K, Resnikoff S, et al: Global prevalence of vision impairment and blindness: Magnitude and temporal trends, 1990-2010. Ophthalmology 120: 2377-2384, 2013.
4. Dhande OS, Stafford BK, Lim JA and Huberman AD: Contributions of retinal ganglion cells to subcortical visual processing and behaviors. Annu Rev Vis Sci 1: 291-328, 2015.

5. Benowitz LI, He Z and Goldberg JL: Reaching the brain: Advances in optic nerve regeneration. Exp Neurol 287: 365-373, 2017.

6. Park KK, Liu K, Hu Y, Smith PD, Wang C, Cai B, Xu B, Connolly L, Kramvis I, Sahin M and He Z: Promoting axon regeneration in the adult CNS by modulation of the PTEN/mTOR pathway. Science 322: 963-966, 2008.

7. Lim JH, Stafford BK, Nguyen PL, Lien BV, Wang C, Zukor K, He Z and Huberman AD: Neural activity promotes long-distance, target-specific regeneration of adult retinal axons. Nat Neurosci 19: 1073-1084, 2016.

8. Liu K, Tedeschi A, Park KK and He Z: Neuronal intrinsic mechanisms of axon regeneration. Annu Rev Neurosci 34: 131-152, 2011.

9. Andrews JL and Fernandez-Enright F: A decade from discovery to therapy: Lingo-1, the dark horse in neurological and psychiatric disorders. Neurosci Biobehav Rev 56: 97-114, 2015.

10. Mi S, Lee X, Shao Z, Thill G, Ji B, Relton J, Levesque M, Allaire N, Perrin S, Sands B, et al: LINGO-1 is a component of the Nogo-66 receptor/p75 signaling complex. Nat Neurosci 7: 221-228, 2004

11. Mi S, Miller RH, Lee X, Scott ML, Shulag-Morskaya S, Shao Z, Chang J, Thill G, Levesque M, Zhang M, et al: LINGO-1 negatively regulates myelination by oligodendrocytes. Nat Neurosci 8: 745-751, 2005.

12. Mi S, Pepinsky RB and Cadavid D: Blocking LINGO-1 as a therapy to promote CNS repair: From concept to the clinic. CNS Drugs 27: 493-503, 2013.

13. Rex TS, Allocca M, Domenici L, Surace EM, Maguire AM, Lyubarsky A, Cellerino A, Bennett J and Auricchio A: Systemic but not intraocular Epo gene transfer protects the retina from light-and genetic-induced degeneration. Mol Ther 10: 855-861, 2004.

14. Fu QL, Hu B, Wu W, Pepinsky RB, Mi S and So KF: Blocking LINGO-1 function promotes retinal ganglion cell survival following ocular hypertension and optic nerve transection. Invest Ophthalmol Vis Sci 49: 975-985, 2008.

15. Inoue H, Lin L, Lee X, Shao Z, Mendes S, Snodgrass-Belt $P$, Sweigard H, Engber T, Pepinsky B, Yang L, et al: Inhibition of the leucine-rich repeat protein LINGO-1 enhances survival, structure, and function of dopaminergic neurons in Parkinson's disease models. Proc Natl Acad Sci USA 104: 14430-14435, 2007.

16. Fu QL, Hu B, Li X, Shao Z, Shi JB, Wu W, So KF and Mi S: LINGO-1 negatively regulates TrkB phosphorylation after ocular hypertension. Eur J Neurosci 31: 1091-1097, 2010.

17. Fu QL, Li X, Yip HK, Shao Z, Wu W, Mi S and So KF: Combined effect of brain-derived neurotrophic factor and LINGO-1 fusion protein on long-term survival of retinal ganglion cells in chronic glaucoma. Neuroscience 162: 375-382, 2009.

18. Kwon HS, Nakaya N, Abu-Asab M, Kim HS and Tomarev SI: Myocilin is involved in NgR1/Lingo-1-mediated oligodendrocyte differentiation and myelination of the optic nerve. J Neurosci 34: 5539-5551, 2014.

19. Chen N, Cen JS, Wang J, Qin G, Long L, Wang L, Wei F, Xiang Q, Deng DY and Wan Y: Targeted inhibition of leucine-rich repeat and immunoglobulin domain-containing protein 1 in transplanted neural stem cells promotes neuronal differentiation and functional recovery in rats subjected to spinal cord injury. Crit Care Med 44: e146-e157, 2016.

20. Mi S, Hu B, Hahm K, Luo Y, Kam Hui ES, Yuan Q, Wong WM, Wang L, Su H, Chu TH, et al: LINGO-1 antagonist promotes spinal cord remyelination and axonal integrity in MOG-induced experimental autoimmune encephalomyelitis. Nat Med 13: 1228-1233, 2007.

21. Li Y, Andereggen L, Yuki K, Omura K, Yin Y, Gilbert HY, Erdogan B, Asdourian MS, Shrock C, de Lima S, et al: Mobile zinc increases rapidly in the retina after optic nerve injury and regulates ganglion cell survival and optic nerve regeneration. Proc Natl Acad Sci USA 114: E209-E218, 2017.

22. Qu J, Wang D and Grosskreutz CL: Mechanisms of retinal ganglion cell injury and defense in glaucoma. Exp Eye Res 91: 48-53, 2010.

23. Shaw PX, Sang A, Wang Y, Ho D, Douglas C, Dia L and Goldberg JL: Topical administration of a Rock/Net inhibitor promotes retinal ganglion cell survival and axon regeneration after optic nerve injury. Exp Eye Res 158: 33-42, 2017. 
24. Trost A, Bruckner D, Kaser-Eichberger A, Motloch K, Bogner B Runge C, Strohmaier C, Couillard-Despres S, Reitsamer HA and Schroedl F: Lymphatic and vascular markers in an optic nerve crush model in rat. Exp Eye Res 159: 30-39, 2017.

25. McKinnon SJ, Schlamp CL and Nickells RW: Mouse models of retinal ganglion cell death and glaucoma. Exp Eye Res 88: $816-824,2009$

26. Wu HF, Cen JS, Zhong Q, Chen L, Wang J, Deng DY and Wan Y: The promotion of functional recovery and nerve regeneration after spinal cord injury by lentiviral vectors encoding Lingo-1 shRNA delivered by Pluronic F-127. Biomaterials 34: 1686-1700, 2013.

27. Huberman AD, Manu M, Koch SM, Susman MW, Lutz AB, Ullian EM, Baccus SA and Barres BA: Architecture and activity-mediated refinement of axonal projections from a mosaic of genetically identified retinal ganglion cells. Neuron 59 425-438, 2008.

28. Pernet V and Schwab ME: Lost in the jungle: New hurdles for optic nerve axon regeneration. Trends Neurosci 37: 381-387, 2014.

29. Cen LP, Liang JJ, Chen JH, Harvey AR, Ng TK, Zhang M, Pang CP, Cui Q and Fan YM: AAV-mediated transfer of RhoA shRNA and CNTF promotes retinal ganglion cell survival and axon regeneration. Neuroscience 343: 472-482, 2017.

30. Wang R, Sun Q, Xia F, Chen Z, Wu J, Zhang Y, Xu J and Liu L: Methane rescues retinal ganglion cells and limits retinal mitochondrial dysfunction following optic nerve crush. Exp Eye Res 159: 49-57, 2017.

31. Rodriguez AR, de Sevilla Müller LP and Brecha NC: The RNA binding protein RBPMS is a selective marker of ganglion cells in the mammalian retina. J Comp Neurol 522: 1411-1443, 2014.

32. Livak KJ and Schmittgen TD: Analysis of relative gene expression data using real-time quantitative PCR and the 2(-Delta Delta C(T)) method. Methods 25: 402-408, 2001

33. Ahn JY: Neuroprotection signaling of nuclear akt in neuronal cells. Exp Neurobiol 23: 200-206, 2014.

34. Crair MC and Mason CA: Reconnecting eye to brain. J Neurosci 36: 10707-10722, 2016.

35. Kwon OJ, Lee ES and Jeon CJ: Density and types of calretinin-containing retinal ganglion cells in rabbit. Neuroscience 278: 343-353, 2014.
36. Groh A, Meyer HS, Schmidt EF, Heintz N, Sakmann B and Krieger P: Cell-type specific properties of pyramidal neurons in neocortex underlying a layout that is modifiable depending on the cortical area. Cereb Cortex 20: 826-836, 2010.

37. Gennarelli TA, Thibault LE, Tipperman R, Tomei G, Sergot R, Brown M, Maxwell WL, Graham DI, Adams JH, Irvine A, et al: Axonal injury in the optic nerve: A model simulating diffuse axonal injury in the brain. J Neurosurg 71: 244-253, 1989.

38. Zhao H, Sapolsky RM and Steinberg GK: Phosphoinositide3-kinase/akt survival signal pathways are implicated in neuronal survival after stroke. Mol Neurobiol 34: 249-270, 2006.

39. Mosyak L, Wood A, Dwyer B, Buddha M, Johnson M, Aulabaugh A, Zhong X, Presman E, Benard S, Kelleher K, et al: The structure of the Lingo-1 ectodomain, a module implicated in central nervous system repair inhibition. J Biol Chem 281: 36378-36390, 2006.

40. Bei F, Lee HHC, Liu X, Gunner G, Jin H, Ma L, Wang C, Hou L, Hensch TK, Frank E, et al: Restoration of visual function by enhancing conduction in regenerated axons. Cell 164: 219-232, 2016.

41. Wilson AM and Di Polo A: Gene therapy for retinal ganglion cell neuroprotection in glaucoma. Gene Ther 19: 127-136, 2012.

42. Pezet S, Spyropoulos A, Williams RJ and McMahon SB Activity-dependent phosphorylation of Akt/PKB in adult DRG neurons. Eur J Neurosci 21: 1785-1797, 2005.

43. Alessi DR, Andjelkovic M, Caudwell B, Cron P, Morrice N, Cohen $\mathrm{P}$ and Hemmings BA: Mechanism of activation of protein kinase B by insulin and IGF-1. EMBO J 15: 6541-6551, 1996.

44. Martin KRG, Quigley HA, Zack DJ, Levkovitch-Verbin H, Kielczewski J, Valenta D, Baumrind L, Pease ME, Klein RL and Hauswirth WW: Gene therapy with brain-derived neurotrophic factor as a protection: Retinal ganglion cells in a rat glaucoma model. Invest Ophthalmol Vis Sci 44: 4357-4365, 2003.

(i) () $€$ This work is licensed under a Creative Commons Attribution-NonCommercial-NoDerivatives 4.0 International (CC BY-NC-ND 4.0) License. 